\title{
The Kindergarten Transition Practices Based on the Tri-Anthropo-Type Paschalidis Model
}

\author{
G. Paschalidis \\ Private Academy of \\ Noospheric Education of \\ Russia,
}

\author{
D. Avlogiari \\ $2^{\text {nd }}$ Kindergarten of Nea \\ Ionia, Greece
}

\author{
K. Chiou \\ Psychologist- \\ Psychotherapist, Greece
}

\begin{abstract}
This study examines the effect of the application of the Tri-Anthropo-Type Paschalidis Model on ensuring a smooth adaptation from the home environment to preschool education, the integration of preschoolers in the kindergarten's environment and the parents' active role in their children's adaptation.

The teacher's observations, questionnaires and structured interviews were used for data collection.

The Model's training course material, questionnaires, experiential activities and parents' counseling were used to carry out the research.

The results showed that the application of the Model helped children manage the first days' stress of environmental change, to feel secure and accepted. It also contributed to enhancing their understanding, interaction and collaboration. The transition practices that took place helped the children's adaptation to and their smooth integration into the school environment and helped the parents to deal with their children's problematic behaviors more effectively. The cooperation between children, parents and the teacher were strengthened.
\end{abstract}

\section{Introduction}

In the beginning of the school year 2015-2016, the teacher was facing, beyond the expected time, adaptation problems, socialization difficulties and lack of cooperation among children, as well as poor communication with the parents. In the past, the teacher, when facing similar situations, as well as incidents of abusive behaviour (verbal and/or physical) among children, had employed the Model and had witnessed dramatically positive change in their behaviour [1]. Therefore, she thought of applying it in this class, too, in order to help the children's better adjustment to their new environment, to propose to parents a more appropriate way to deal with their children in this critical phase of their lives, and finally to facilitate her own communication with the parents. Research suggests that a large percentage of kindergarten children do not successfully transition to school [2]. As a result, a number of school transition initiatives have been developed by educators and policy makers to address the difficulties young children may experience upon kindergarten entry [3]. When a child starts kindergarten, from member of a family, he becomes member of a group of same-age children. In school, the child has to share everything with his peers, school material, toys, even the adults' attention, losing thus the exclusivity he enjoyed at home. How the child accepts his new role also influences his school experience. In kindergarten, the child meets other children of the same age with different development, who speak different languages and live in different family enviroments. These differences are opportunities for the children to learn from one another, but they can also cause difficulties in their adjustment [4]. Moreover, other research indicates the important role of parents in this transition phase to kindergarten and suggests a need for familyschool partnership during this critical juncture. In a study, it was examined how families with typically developing children look at the transition to kindergarten. Caregivers expressed interest in receiving more information about the transition process, including information about kindergarten expectations, as well as learning how to assist their child during the kindergarten transition process [5]. Likewise, the goal of the present study was to inform parents and offer them specific counselling. The contemporary pedagogy has equipped us with various techniques for assisting the transiion process. Research has found that engagement in more types of transition practices was predictive of heightened prosocial behaviors among children, but was not associated with children's attention or academic outcomes.

Examination of specific types of practices found that transition activities geared toward parents were associated with children's heightened academic skills in kindergarten. These results suggest that specific types of transition practices are linked to particular aspects of children's functioning [6].

The Tri-Anthropo-Type Paschalidis Model has multiple applications, its application in various levels of education being one of them [1] [7] [8]. 
According to the Model, every person belongs to only one of three distinct personality, Types A, B or $C$, differentiated mainly by brain function and plasticity. Personality Types are determined by individual differentiations in activation, volume and functional connection of the temporal lobe, the amygdala and the hippocampus. Furthermore, there are some complementary brain structures that play a significant role in the neural signal transmission and brain function of each Type [9].

The Model proposes certain transition practices according to and depending on the children's personality Type(s) and the personality Type(s) of their parents. Regarding the teacher, this knowledge is the key to successful transition.

Maternal, paternal and children behavior are also outlined in detail in the Model, along with the psychopathology that can develop, either individually or at relationship level. Family relationships have been profiled and mapped, and detailed psychograms of the personalities and behaviors have been formulated for fathers, mothers and children, according to their Types, A, B or C.

As far as the main characteristics of the parents/ guardians are concerned, those who belong to Type A are abrupt, impatient and maintain a relationship of friendship based on trust with their children. Type B parents are affectionate, overprotective; they always give their children advice on/about everything and constanlty worry that something bad will happen to their children. Type $\mathrm{C}$ parents are very giving, but persistent and bossy; they prepare their children for a tough life ahead.

As far as the main characteristics of the children are concerned, Type A children are independent, impulsive, they easily adapt, get carried away, they cannot withstand pressure, constraints and tight schedules. They do not need their parents' presence constantly and can easily become independent. They easily relate to people around them as long as they find communicating with them interesting. They are not attached to people or toys, which allows them to adjust easily to new environments, as long as these are pleasant. However, because they like their daily routine and want to feel at ease, they do not like changes in the environment around them. When they are under stress, they display irritability and react with shouts and squeaks. They feel under pressure when their freedom (of choice) is threatened, and in particular when they are interrupted while playing. When they are forced to be in a place they do not want to, they become unfriendly, aloof, and distant. When someone forces them to communicate while they do not want to, they become abrupt and irritable. Table 1 depicts Type A children's personality traits and behavior.
Table 1. Type A children's personality traits and behavior

\begin{tabular}{|l|}
\hline Type A children's personality traits and behavior \\
\hline Independent \\
Easily adapting \\
They get carried away \\
Impulsive \\
They cannot withstand pressure, constraints and \\
tight schedules \\
They do not like changes \\
When under stress, they become abrupt and \\
irritable, they shout and scream
\end{tabular}

Type $\mathrm{B}$ children tend to be dependent on their parents more than Type $\mathrm{A}$ and $\mathrm{C}$ children, they adapt to new environments slowly, because they need time to feel comfortable in them. They tend to comfort other children when they cry, they are talkative and polite. They tend to mimic more than other children various behaviors in order to feel accepted and loved by others and have a low self-esteem/selfconfidence. They are shy and need to feel safe. When they are under stress, they get angry and keep whining. When they feel stressed, while being in a familiar environment, they become demanding, mischievous and react with anger. In order to be loved by others and become part of a team, they adopt a passive and obeying behavior. They express themselves only when they feel safe. Table 2 depicts Type B children's personality traits and behavior.

Table 2. Type B children's personality traits and behavior

Type B children's personality traits and behavior
Dependent on their parents
Slow adaptation
Talkative
Polite
Shy
They have low self-esteem/self-confidence, they
need to feel safe
They adopt a passive and obeying behavior
When under stress, they get angry and whine

Type $\mathrm{C}$ children are bold, competitive, and active with a strong will. They like to try things in order to acquire experiences, they do not easily change their mind. They are very disciplined and persistent when they want to achieve a goal, and want other children to follow them and show the same stamina and will. But, because other children do not act as they expect them to, Type $\mathrm{C}$ children get hurt, think that other children are unfair to them and, in the end, they feel rejected. They feel insecure. When they are under stress, they become intensely active, they get 
stubborn and become disobedient. They feel insecure and make up imaginary stories in order to feel accepted by others [7]. Table 3 depicts Type C children's personality traits and behavior.

Table 3. Type C children's personality traits and behavior

\begin{tabular}{l} 
Type $C$ children's personality traits and behavior \\
\hline Bold \\
Competitive \\
Persistent, strong willed \\
Self-disciplined \\
They feel insecure \\
They experience feelings of rejection \\
When under stress, they become intensely \\
active, get stubborn and become disobedient.
\end{tabular}

The objectives of the intervention were to examine whether the Model helped:

a) to facilitate the children's transition from their home to the kindergarten

b) their integration in the new environment, achieving cooperation and good interaction among them, and

c) to improve communication among the teacher and parents/guardians and achieve efficient counseling of parents regarding the children's adaptation to the new environment.

\section{The research}

The intervention took place as a Health Educational Program entitled «The Three Paschalidis' Types as a game in our school» from September 2015 to January 2016, twice a week.

The teacher in the class was mainly responsible for the intervention and was assisted by G. D. Paschalidis as facilitator/external collaborator offering regular feedback concerning her practice and research, and by a specialized in the Model psychologist, who helped mainly in the reflection phases and the parents' counselling.

The intervention was connected with the Kindergarten's Curriculum and was linked to the following subjects: language, writing, mathematics, social sciences (human environment and interaction), and creative expression (visual arts, drama, puppetry etc).

\subsection{The identity of the class}

The kindergarten class consisted of 18 children ( 8 boys and 10 girls), aged 5 to 6 , in Southern Attica, Greece. All children understood and spoke Greek.

\subsection{Material, methodology, activities}

Quality observations, questionnaires, structured interviews under the form of a quiz, drawings/ pictures from the class, and the class teacher's journal were the research tools used.

Triangulation was used to ensure the validity of the collected data and the intersubjectivity of the findings. In particular, three different ways of data collection were used (observation, questionnaires, structured interviews/counselling sessions) and they were collected from three different sources (teacher, children and their parents).

The research process consisted of three main steps.

First step: The class teacher attended a specialized training course on the application of the Tri-AnthropoType Paschalidis Model in preschool education, and adaptation to new environments, taught by G.D. Paschalidis himself, where she was provided with the necessary guidelines and material for the research. The material included detailed information about every child's personality Type, traits, and behavior during their transition from their home to the kindergarten and their integration into the new environment. Furthermore, the material contained information about the appropriate way to approach parents according to their Type, for them to help the adaptation of their children to the new environment. Moreover, it contained suggestions about parental practices according to the personality Types of both parents and children.

Second step: Observation and recording, for one month from the beginning of the school year, of the children's and parents' behavior. The teacher could identify every child's personality Type by examining their behavior, during their separation from their parents in the morning and when they were participating in free activities in the school yard. In addition, she could identify the parents' Type from the way they were reacting toward their children. The teacher's intervention included four group sessions with the parents, held for two hours once a week. Individual sessions also took place, when necessary. Counselling was organized as follows: The first group session was divided into four sections, where parents were asked: a) to share their thoughts and feelings about their children's new start at school and how this affected the family life; b) to say how they prepared their children for the upcoming change and how their children reacted on the first school day; c) to say how they prepare themselves every morning before driving their children to school and what they tell them shortly before leaving them at school; and d) to say how they spend their free time with their children, when they are back from school. At the end of the first group session, two questionnaires were given to the parents: the first one to identify their own 
Type (The Tri-Anthropo-Type Pachalidis Questionnaire), and the second one to identify the child's Type (The Tri-Anthropo-Type Paschalidis Questionnaire for pre-school children). In the second meeting, parents were asked to say: a) how they evaluate themselves as parents and which elements of their own personality they consider as strengths and weaknesses; b) how they would describe their child and their relationship with it; c) with which aspects of their everyday life with the child they find it difficult to cope, for example putting their child to bed, setting boundaries, ect. At the end of these two sessions, parents were introduced to the TriAnthropo-Type Paschalidis Model and the parental Type they belong to according to their personality traits and their parental behavior. The answered questionnaires, the statements of the parents during the group sessions, as well as the teacher's observations were used to determine each parent's Type. In the third group session, parental behavior according to personality Type was in detail described and parents began speaking of their own family life experiences. In this meeting, there were presented and analyzed ways of dealing with a child's problematic behavior, according to the child's personality Type and the personality Type of his/her parents. There were analyzed each child's psychological and physical needs according to his/her personality Type. There were also made suggestions to the parents about how to reinforce the positive elements of their parental Type in order to bring happiness and tranquillity in their family. These suggestions also aimed at helping children to this new phase of their life, i.e. the transition from home to school environment. There were some suggestions about how parents should react when they leave their children at school and how they should welcome them when they pick them up from school.

Third step: The Tri-Anthropo-Type Paschalidis Model was introduced to the children, through three sections of activities entitled: a) "Getting to know the Tri-Anthropo-Type Paschalidis Model", b) "Getting to know my personality Type", c) "Getting to know the personality Type of my schoolmates and my teacher, applying the Model in my class". During the first section of activities, the series of the children's stories, by G. Paschalidis, were used to study, discuss and identify the characteristics of the three Types A, B and

C. The findings of the parents' interviews and of the children's quizzes were used, in the second section. The third section was aiming at teaching the children how to recognize their Type. Report boards were created, where the children wrote their name and Type. They counted how many children in the class belonged to each Type. They also created individual identity cards, where they wrote their Type next to their picture, and they drew their future occupation. They ascertained that their desires and characteristics were exactly as the Model described. "The magic stick" was used, a role-play game to recognize the behavior of the children's Type and reconcile them whenever they had an argument. In this game, a child touches the children who have an argument with a magic stick, like a wizzard. The children distinguish certain personality traits of their Type and discuss them in the classroom to improve their behavior. When this happens, the wizzard touches the children again in order to change their behavior and make them feel better. "The melting iceberg", an experiential exercise about the management of vulnerable aspects of each personality Type, was used. Children were told that every time they experience negative feelings they demostrate their personality Type's vulnerable aspects and this makes them look like an iceberg. But when irritability (Type A), fear (Type B) or persistence (Type C) go away, then the "iceberg melts", becomes a "river" and everyone comes to drink fresh water from it. This exercise was used to recognize the children's negative behavior attributed to their personality Type, discuss it in the classroom and find solutions to improve their behavior.

Other creative activities that helped them understand the personality Types were the following: the children played puppet theatre and role play, and they dramatized the tales in "public" in front of their peers in the co-located school. They wrote their own tale titled "The stubborn squirrel", which was about the behaviors of the three Types, and what they could together achieve through love and collaboration. Activities aiming at introducing to the children the nutritional principles of the Model and the Typespecific nutritional requirements followed, and they also cooked suitable meals for their Type.

\section{Results}

According to the questionnaires, $16,67 \%$ of the children belonged to Type A, $44,44 \%$ to Type B, and $38,89 \%$ to Type C. According to the questionnaires filled by the parents, $22,22 \%$ of the fathers were Type A, 44,45\% Type B, and 33,33\% Type C; $11,11 \%$ of the mothers were Type A, 55,56\% Type B, and 33,33\% Type C. The charts below show the percentage of children's and their parents' personality Types.

Regarding the behaviour of the children and their parents/guardians during their separation the first month of adjustment, the teacher recorded behaviors, as reported in the Model, and she noted them in her journal: "The children that belonged to Type A were agitated and frustrated, threw violent tantrums, hooked onto their parents squeaking loudly, and they did not want to stay $\alpha \tau$ school. Their parents were strict; they spoke with a firm voice, explaining that all children must go to school. 
Childrens' personality Types

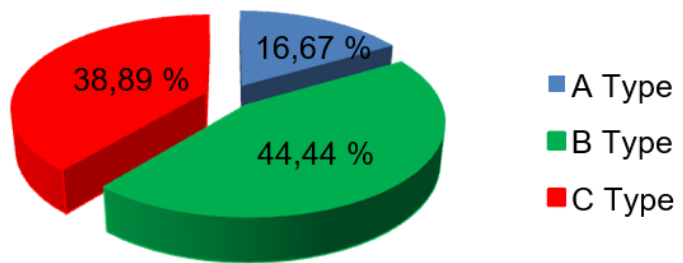

Figure 1. Children's personality Types

Fathers' personality Types

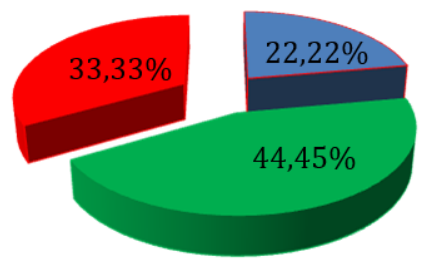

口A Type

B Type

aC Type

Figure 2. Fathers' personality Types

Mothers' personality Types

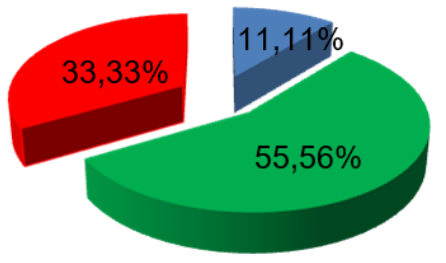

- A Type

- B Type

-C Type

Figure 3. Mothers' personality Types

The children that belonged to Type B were crying, holding their parents from their clothes, asking them to stay in the class, too. Their parents were analyzing in detail, why the children "must" stay in the kindergarten, although the children did not calm down by their words. Finally, the parents were leaving, after giving them promises that they would call them or come to pick them up earlier, and gave them many kisses. Their nervousness was overwhelming and they passed it on to their children. The children that belonged to Type $\mathrm{C}$ were crying, they were aggressive toward their parents following them when they were leaving. The parents were scolding them, they were comparing them to the other children who did not react this way, and they were leaving, threatening to punish them at home, unless they calm down". Throughout the first period of the children's adjustment, the teacher applied the suggested by the Model interventions. Every day, she used to give a toy or a candy, as a reward, to the Type A children and she tried to make them forget the separation from their parents and to calm them down. This practise resulted in the children becoming involved in playing, and making new friends. They participated with pleasure in the activities. She treated Type B children with affection and gave them special attention. She kept them close to her to make them feel secure. She introduced them to the other children and proposed specific games to them. As they were continuously asking either about their mother's return or to leave, the teacher answered patiently, caressing them. She was behaving toward them as mother. Gradually this behavior helped them feel comfortable in the class, and they were no longer experiencing the separation anxiety from their parents. The teacher hugged the Type $\mathrm{C}$ children, she gave them initiatives, making them feel special and acceptable. For example, she asked them to be her assistants or gave them a mission. Thus, she helped them relinquish their stubborn denial of entering the class and participate in the activities with interest. As the kindergarten teacher knew that Type $\mathrm{C}$ children need great attention and acceptance, she was always alert.

As for the smooth integration of the children, by applying the principles of the Model, the teacher noticed that the children were easily staying at school and displayed a great change in attitude and mood. They were creatively involved in a climate of confidence and joy. Learning the Model through play gave the children the opportunity to understand themselves and their behavior. Moreover, it helped them understand their friends' behavior. Every activity and learning process became easier and enjoyable, as their interaction was enhanced. Type A children learned to comply with the class rules, be less intractable, and had milder reactions when they were not allowed to do something. They also learned to arrange and take care of their personal belongings. Type B children gained confidence; they did not hesitate to express their feelings and desires. Their behavior changed, they were less shy and anxious. They became more assertive. Type $\mathrm{C}$ children became less competitive, they did not stubbornly insist on their desires. They cooperated, shared harmoniously and enjoyed activities.

\subsection{Counseling group sessions}

Almost all parents attended the counseling group sessions. In the first group session, differences in the way parents dealt with their child's transition to the new environment and the way they prepared their child for it, began to be obvious. 83,33\% of Type A 
parents considered the transition to school as something easy, and stated that they saw no reason to discuss with their child about it, at home. They also thought that their child would easily overcome any possible difficulty and it would integrate into the new environment. Even when their child had intense outbursts, they kept smiling and considered them normal. They thought that these outbursts would fade out with time, although they felt very irritated by their child's behavior. As far as the morning preparation for school is concerned, they stated that they are very often in a hurry, and they get irritated when their child does not obey them. But even if there is much tension during the morning preparation at home, when they get to school, they have already calmed down and have left behind the morning's difficulty. When being at work, they are sure that their child will not have any problem, even if the teacher tells them the opposite. As parents they are characterized by free thinking and a tendency to face every issue as something that can be easily resolved, but sometimes this results in failure to pay attention to the child's emotional needs. $72,22 \%$ of Type B parents said that they were preoccupied about their child's transition to school, even if there was no obvious reason about it. They were worried when their child hesitated to enter the school and were trying to convince it to do so, even though they were thinking that their child's behavior might be hiding a more serious problem. During morning preparation for school, they stated that everything was going at a slow pace and this made them nervous about arriving in time. There have been many times when parents argued and accused one another about not organizing things right in the morning. About their behavior upon arriving at school, they stated that they usually carry their child's bag and take care of every single detail before leaving. They keep saying goodbye to their child before leaving, as if this morning separation is equally hard for them. Type B parents stated that while they are at work they often think about their child and wonder whether he is having a hard time at school. But they said that these thoughts do not hinder them from being focused on their job. As parents they are very caring, but most of the time this leads them to restlessness and fear that a problem may come up. This happens even if there is no actual problem or if there is something that can be easily resolved. $75 \%$ of Type C parents considered the transition to school a challenge and wanted to prepare their children, so that they be ready for it, emotionally and practically. While at home, they talked to their children about school as something new, interesting and pleasant. They explained to them how they should behave in order to overcome obstacles and what they, as parents, expect from them. For example, they asked them to listen to the teacher and not create any problems, a rule that they should follow every day. Type C parents do not expect that their children will face any particular problem. However, if there is a problem, they think that it can be always overcome with the threat of depriving some privileges. They also stated that their children will be obedient, if they as parents are able to keep the boundaries. As far as morning preparation is concerned, they said that there is discipline and obedience and when there is some problem they discuss it with their child for a while but soon insist that the child should obey their orders. When they arrive at school, they are calm and totally organized. They are waiting for their child to put his/her things in order, check that everything is done the right way and leave without any particular greetings. While they are at work, they think about their children but do not worry about them even if they feel ill. They worry about their children only when their illness is really dangerous for their health. Type C parents are close to their children, they demand from them to fully comply with the family rules and train them in order to behave correctly and achieve high scores at school.

During the second and third group sessions, of parental counseling, almost all parents stated that all the information about the personality Types had been very helpful and that it helped them recognise many elements of their behavior, their thoughts and emotions. They said that counseling interventions had very positive results as regards their ability to prepare their children for the new school environment and understand how they could improve the emotional preparation of their children, the morning routine and their separation when they arrive at school. Additionally, they emphasized that counseling helped them face other issues at home with their children. They said that they were able to understand their relationship with their child better and to see clearly what caused difficulties in the relationship with them. They also stated that the knowledge of their personality Type and the personality Type of their children helped them not only to find ways to overcome the obstacles in their relationship with the children but also to feel good as parents. Type A parents said that the awareness of their parental behavior helped them be more patient, more affectionate and talk more with their children. Type B parents said that the intervention helped reduce their concerns, overprotection and continuous advising. Type $\mathrm{C}$ parents were helped to be less pressing and punitive; they trusted and hugged their children more.

The teacher noted: "A Type C boy was crying persistently for three hours and demanding from his mother to pick him up. He was afraid that she abandoned him and he was looking insistently for her. In the counseling sessions, it was explained to the mother that it is necessary to inform her child every day on her working schedule and to explain to him that it is very important for her to work. She 
should express how much she loves him on every occasion and reassure his feelings of rejection. The mother agreed to follow the teacher's advice and as a result the boy calmed down and was happily playing, without continuously asking for his mother's return". And she continued: "A Type B boy was crying almost every day. He was watching out of the window waiting for his mother. A Type B girl was worrying on a daily basis that her mother would not come to get her (she had already lost her father). Both mothers were asked to explain in detail, every single day, very patiently, where they were going to be, what they were going to do, when they would return, and what was the schedule of the day. The first child felt safe, his stress level reduced and was concentrating on the activities. The second child felt confident and from the lonely girl that she was, she became more social, made friends and became popular". "A Type A girl used to abuse other children physically, was screaming, got on the tables and chairs, was very impulsive and hyperactive. She created problems in the classroom even from the first days of school. She could only understand rules if they were visualised. The teacher informed the girl's parents about her personality Type and they agreed to give her little treats or rewards in order to calm her down and to give her more space and time at home so that she could feel free to decide on some matters that were important to her. Also, when the teacher explained to other children the girl's personality traits and the true reasons of her behavior, they began to accept her behavior. After two months, the girl gradually began to sit on her chair for more time, listened to the fairy-tales in the classroom and participated in group exercises by giving practical solutions. She was calmer and her hyperactivity was limited enough, so that she did not create tension in the classroom.

\section{Discussion}

Scientific research recognizes that a successful transition to school can increase the likelihood of positive social, emotional and academic outcomes for children [10]. It is well accepted that this transition is a very challenging stage in a child's life. The child leaves home security and mother's care and is forced to adjust to an unfamiliar environment. It has to follow rules and expectations and work with new people, both teachers and schoolmates. This change is a major shock for the child and each child adapts itself differently to the new situation depending on the personality Type it belongs to [11].

Our findings confirm that children vary in their ability to adapt to school environment and that, if they are treated by both parents and teacher according to their personality Type, they manage to cope with all the difficulties and make the transition from home to school a pleasurable and creative process.

During morning separation, three distinct children reactions were observed by the teacher. Children belonging to Type A personality were screaming, Type B children were crying and holding their parents from their clothes and Type $\mathrm{C}$ children were crying and were becoming aggressive toward their parents. According to the bibliography [11], Type A children are quite independent and can be easily weaned off their home and their family. However, they need some time to feel welcome to the school's environment. They can become very nervous and react with panic and hysteria when under stress. That is why they scream and rampage around their parents. Type B children are afraid of the kindergarten (are more prone to separation anxiety) and prefer to avoid it and stay home with their parents. A predictable routine allows Type B children to feel safe, whereas sudden changes make them feel insecure [11]. That is why their transition to the kindergarten is a major change in their life. During their separation from their parents they hide behind their legs, cry and ask for caress and consolation. Type $\mathrm{C}$ children experience feelings of abandonment and rejection from their parents when they go to school for the first time, regardless of their parent's reactions. At the time of separation, they hold their parents too tight, cry loudly and when their parents leave, they stand still [11].

The kindergarten teacher, therefore, had only three different types of children to cope with, who had completely different needs, during the first separation from parents as well as the integration into school. Regarding the behavior of children at school and in accordance with the bibliography [11], Type A children get bored easily, cannot withstand stress, restrictions and strict schedules and feel comfortable only when they feel free. However, if an immediate bribe is offered to them, they forget their problem and calm down. They easily adapt to a new environment and they actively participate in group activities with joy and enthusiasm. Type B children need much time to adapt to a new environment and they do so only if they feel secure and are given affection. Therefore, the teacher has to help them feel safe, encourage them and guide them. He/she has to show them which toys they should use and introduce them to other children in order to play with them. Type $\mathrm{C}$ children have a constant need for recognition of their abilities and acceptance, thus the teacher must make them feel special.

The teacher, by following the instructions found in the bibliography offered bribes to Type A children, affection and safety to Type B children and gave a lot of hugs to Type $\mathrm{C}$ children. As a result, children became bold, unworried and calm in a very short time. All children in the class managed to cope well with the feelings of uncertainty and insecurity 
and the appropriate emotional environment was built for all of them. The children were able to integrate smoothly into the broader social environment and to acquire social skills. They learned to coexist, cooperate and work as part of a team.

The adaptation from the home environment to preschool education is not only a teacher's work, but the parents' work as well. Scientific research recognizes the parents' involvement as a factor that contributes to early development, transition to school and the child's future school success [12]. Unfortunately, even teachers that have been trained in communication skills, strive to establish effective partnerships with parents. The only model that introduces teachers' strategies that pull down all communication barriers between teachers and parents and actively promotes parental involvement is the TriAnthropo-Type Paschalidis Model. According to the Model, the teacher counsels parents on how to avoid the extreme behaviors that derive from their own personality Type and on how to successfully approach their children according to the personality Type they belong to. Type A parents should be discreet enough not to make their children feel that they are being under strict control and repression, and at the same time they should not be indifferent and give them the impression that they do not care. Type B parents should trust their children, appraise them on every single occasion and stop constantly advising and scolding them. They should let them be free and independent. Finally, Type C parents should not force their children into doing too many things and setting them new goals constantly. They should teach them to enjoy life and be less competitive. They should not compare them with other children and let them express themselves. The observations of the teacher have helped her understand that home-to-school transition is not just an experience for the child itself. The family and the teacher have also an important role to play, which is crucial to the effectiveness of the transition experience. When teachers and parents work together by applying the Tri-Anthropo-Type Model and children feel that they have their support, starting school can be a positive and exciting experience.

\section{Conclusion}

The application of the Tri-Anthropo-Type Paschalidis Model in the preschoolers' adaptation to the kindergarten had unquestionable positive results. The teacher created an emotionally supportive and behaviorally well-managed classroom community, where children were feeling safe, supported, bonded, and motivated by the interactions they had with their teacher and their classmates, and therefore they integrated well into the new environment. At the same time, the teacher achieved effective communication with the parents that was the foundation for a strong teacher-parent partnership, which promoted parental involvement and ultimately supported the children's adaptation to the kindergarten.

The Tri-Anthropo-Type Paschalidis Model embraces students, teachers and parents all over the world as it relies on the existence of only three human personality Types. It creates a positive and productive educational environment based on the understanding of oneself and of others, on acceptance, collaboration and positive reinforcement, improving the wellbeing of children. Self-knowledge and hetero-knowledge are a prerequisite for meaningful relationships among all members of the school community. These relationships can now be guaranteed relationships of acceptance and love. This happens because they are no longer subject to subjective interpretation of actions and behaviors but to the objective reality that the Model reveals. The acceptance and love are the ideal ground for the cultivation of learning.

\section{References}

[1] G. Paschalidis, D. Avlogiari, P. Karaviti, and K. Chiou, "Applying the Paschalidis Tri-Anthropo-Type Model in the Kindergarten: A Case Study", International Journal for Cross-Disciplinary Subjects in Education, Infonomics Society, Essex, 2015, pp. 2106-2110.

[2] S. Rimm-Kaufman, R. Pianta, and M. Cox, "Teachers' judgments of problems in the transition to kindergarten", Early Childhood Research Quarterly, Ablex Publishing Corporation, New York, 2000, pp. 147-166.

[3] L. McIntyre, T. Eckert, L. Arbolino, F. DiGennaro Reed, and B. Fiese, "The Transition to Kindergarten for Typically Developing Children: A Survey of School Psychologists' Involvement", Early Childhood Education Journal, Springer Publishing, New York, 2000, pp. 203210.

[4] Cooper, S. and K. Dukakis, Kids Can't Wait to Learn Achieving Voluntary Preschool for All, Preschool California, California, 2004.

[5] L. McIntyre, T. Eckert, B. Fiese, F. DiGennaro Reed, and L. Wildenger, "Transition to kindergarten: Family experiences and involvement", Early Childhood Education Journal, Springer Publishing, New York, 2007, pp. 83-88.

[6] K. Cook, and R. Coley, "School transition practices and children's social and academic adjustment in kindergarten", Journal of Educational Psychology, American Psychological Association, Washington, 2017, pp. 166-177.

[7] G. Paschalidis, "The Paschalidis Tri-Anthropo-Type Model in Education: Three Learning Profiles, Three Teaching Styles", Literacy Information and Computer Education Journal, Infonomics Society, Essex, 2014, pp. 1511-1517. 
[8] G. Paschalidis, P. Papathanasiou, P. Karaviti, and K. Chiou, "The Effect of the Paschalidis Tri-Anthropo-Type Model on Lower Secondary Education Children: A Case Study", International Journal of Innovative Business Strategies, Infonomics Society, Essex, 2015, pp. 39-44.

[9] Stathopoulou, A. and Paschalidis, G. (2012) "Genetically determined differences of the three structures of limbic brain system determine three distinctive and unique personality types: a special key for understanding connection between brain function and its plasticity with health prevention", in Proceedings of 18th International Neuroscience and Biological Psychiatry Conference, New Orleans, pp. 22-23.

[10] Astbury, B., Evaluation of Transition: A Positive Start to School Pilots. Centre for Program Evaluation, Melbourne, 2009.

[11] Paschalidis, G., Tri-Anthropo-Type Paschalidis Education, Paschalidis editions, Thessaloniki, 2014 (published in greek).

[12] J. Pelletier and J. Brent, "Parent participation in children' school readiness: The effects of parental selfefficacy, cultural diversity and teacher strategies", International Journal of Early Childhood, Springer, Netherlands, 2002, pp. 45-60. 